
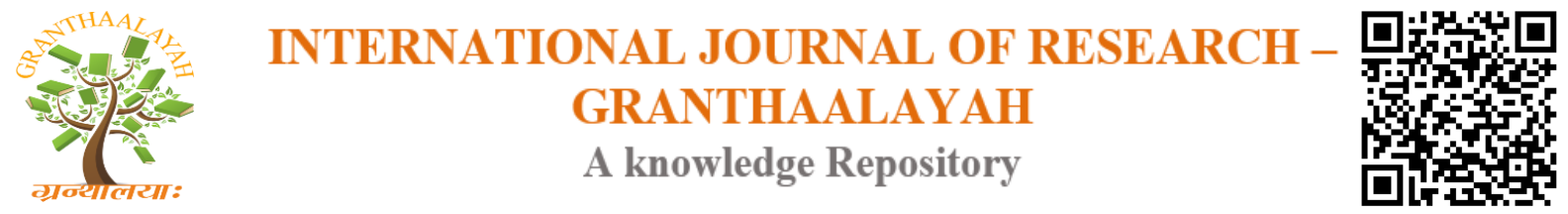

Social

\title{
ATTITUDE OF PLUS TWO STUDENTS TOWARDS PUBLIC EXAMINATION IN RELATION TO PARENTAL PRESSURE
}

\author{
S. Vinolin Chrysolyte ${ }^{1}$, Dr B. William Dharma Raja ${ }^{2}$ \\ ${ }^{1}$ M.Ed Student, Department of Education, Manonmanium Sundaranar University, Tirunelveli - \\ 627 012, INDIA \\ ${ }^{2}$ Head, Department of Education, Manonmanium Sundaranar University, Tirunelveli - 627012 , \\ INDIA
}

DOI: https://doi.org/10.29121/granthaalayah.v4.i10(SE).2016.2436

\begin{abstract}
This study examines the attitude of plus two students towards public examination and its relationship with parental pressure. The sample of the study comprised of 386 plus two students from Tirunelveli district. The authors employed survey method for collecting the data and they were analysed using descriptive and inferential statistical techniques. It was found that there is a significant relation between the attitude of students towards +2 public examination and parental pressure.
\end{abstract}

Keywords:

Parental Pressure, Public Examination, Students.

Cite This Article: S. Vinolin Chrysolyte, and Dr B. William Dharma Raja, "ATTITUDE OF PLUS TWO STUDENTS TOWARDS PUBLIC EXAMINATION IN RELATION TO PARENTAL PRESSURE" International Journal of Research - Granthaalayah, Vol. 4, No. 10: SE (2016): 9-13.

\section{INTRODUCTION}

Parental pressure is an unknowing burden of a parent shown towards their children in order to make their lives in progress. The pressure maybe there in any type of family and the pressure may be in relation to school for achieving the highest marks. Parental pressure is normally experienced by children in school, sports, arts and careers. All parents love to see their children excelling in curricular and co-curricular activities and sometimes over expect from their children.

The term 'parental pressure' refers to the efforts that parental behaviors have on children's functioning (Watson \& Skinner, 2004). Parental influence emerged as pressure and stressful. The children believe that their parents had high expectation on them. Generally, students fear to take an examination and doing examination normally students become nervous and stressful. It is 
commonly believed that examinations are the test of merit. It is not true, always. Any have it is an essential evil.

\section{SIGNIFICANCE OF THE STUDY}

Every parent wants their children to lead a very successful life. So they give pressure on children and it will affect the children emotionally and physically. When parents give pressure to their children in studies and compel them to attend special classes they have lot of stress. Parents' unrealistic expectations with their wards put continuous pressure on them to do well in their academic activities.

Parents want their children to get high marks in public examination. After the public examination in +2 they have to choose a promising course. When they don't get the expected course, they get frustrated. Parents' pressure on their children regarding their study builds an unwanted burden on them.

\section{OBJECTIVES OF THE STUDY}

1) To find out significant difference, if any, in attitude of plus two students towards public examination with regard to select background variables;

2) To find out significant difference, if any, in parental pressure on plus two students relating public examination with regard to select background variables; and

3) To find out significant relation, if any, between attitude of plus two students towards public examination and parental pressure.

\section{METHOD USED FOR THE STUDY}

Survey method was adopted for the study.

\section{SAMPLE}

The population for the study was plus two students of Tirunelveli district. The sample size for this study was 386, selected by simple random sampling technique.

\section{TOOL USED}

In the present study, the authors prepared two self-constructed scales namely, ViWi's Scale on parental pressure and ViWi's attitude scale on +2 public examinations with three points and 20 items.

For establishing the face validity, the tool was pruned with field experts. The reliability was established by split-half method and the reliability co efficient was found to be $r=0.767$

\section{ANALYSIS OF DATA}

The statistical techniques used for analysis of data are ' $t$ 'test, ' $F$ ' test and pearson's correlation. 
Table 1: Significant of Difference in Attitude towards Plus Two Public Examinations

\begin{tabular}{|l|l|l|l|l|l|l|}
\hline Background & variable & \multicolumn{1}{|c|}{$\mathbf{N}$} & Mean & SD & t-value & p-value \\
\hline Gender & Male & 226 & 71.932 & 9.350 & & $.006^{* *}$ \\
\hline $\begin{array}{l}\text { Locality of } \\
\text { School }\end{array}$ & Female & 160 & 74.614 & 9.301 & 2.783 & \\
\hline $\begin{array}{l}\text { Medium of } \\
\text { instruction }\end{array}$ & 120 & 72.986 & 8.574 & .081 & $.935^{\mathrm{NS}}$ \\
\hline
\end{tabular}

The above table shows that there is no significant difference in attitude of +2 students towards public examination with regard to locality of school and medium of instruction and there is significant difference in the attitude of students towards +2public examination with regard to gender. The mean scores show that the attitude of female higher secondary students is more towards the +2 public examinations than male higher secondary students.

Table 2: Significant of Difference in Parental pressure on plus two students relating Public Examination

\begin{tabular}{|c|c|c|c|c|c|c|}
\hline Background & variable & $\mathbf{N}$ & Mean & SD & t-value & p-value \\
\hline \multirow[t]{3}{*}{ Gender } & Male & 226 & 65.744 & 12.479 & \multirow{3}{*}{1.139} & \multirow{3}{*}{$.255^{\mathrm{NS}}$} \\
\hline & & & & & & \\
\hline & Female & 160 & 67.218 & 12.583 & & \\
\hline \multirow{2}{*}{$\begin{array}{l}\text { Locality } \\
\text { school }\end{array}$} & Rural & 120 & 67.347 & 11.966 & \multirow{2}{*}{1.044} & \multirow{2}{*}{$.297^{\mathrm{NS}}$} \\
\hline & Urban & 266 & 65.908 & 12.768 & & \\
\hline \multirow{2}{*}{$\begin{array}{l}\text { Medium of } \\
\text { instruction }\end{array}$} & Tamil & 317 & 66.687 & 12.426 & \multirow{2}{*}{1.116} & \multirow{2}{*}{$.265^{\mathrm{NS}}$} \\
\hline & English & 69 & 64.830 & 12.960 & & \\
\hline
\end{tabular}

NS-Not Significant at 5\% level

The above table shows that there is no significant difference in parental pressure on plus two students towards public examination with regard to gender, locality of school and medium of instruction.

Table 3: Relation between Attitude of plus two students $(\mathrm{N}=386)$ towards public examination and parental pressure

\begin{tabular}{|l|l|l|l|l|}
\hline Variables & Mean & SD & r value & p value \\
\hline $\begin{array}{l}\text { Parental Pressure } \\
\text { And Attitude towards } \\
\text { Public examination }\end{array}$ & 66.355 & 12.527 & 0.372 & $0.000 * *$ \\
\hline
\end{tabular}

** Significant at $1 \%$ level 
It is inferred from the above table that $\mathrm{p}$ value is lesser than 0.01 . Hence the null hypothesis is not accepted at $1 \%$ level of significance. It reveals that there is a significant positive relationship between higher secondary students' attitude towards +2 public examinations and parental pressure.

\section{FINDINGS}

1) The attitude of female higher secondary students is more favorable towards the +2 public examinations than male higher secondary students.

2) There is no significant difference in attitude towards plus two public examinations with regard to locality of school and medium of instruction.

3) There is no significance difference in parental pressure on students relating public examination with regard to gender, locality of school and medium of instruction.

4) There is a positive relationship between higher secondary students' attitude towards +2 public examinations and parental pressure.

\section{RECOMMENDATIONS}

In the light of the findings of the study, the authors give the recommendation as below:

A statistics is given by Tamil Nadu government (http://www.tn.results-nic.in/hscresults.html). The percentage of boys in 2015 plus two public examination is $87.05 \%$ which is less than $5.54 \%$ that of girls. The percentage of boys in 2016 plus two public examination is $84.45 \%$ which is less than $6.33 \%$ which is less than that of girls. So the parental pressure is needed for male children. The pressure be more psychological and practical, the children should be expected to achieve more than what they could. Since the children are at the adolescence stage, the deals with them should be accordance with that.Parents should act as a guide. They should not torture their children. They should motivate and make enjoying in their studies. Parents should not make their studies as a burden. Children should not know that they are pressurizing by their parent. Children should be under their control. Schools should periodically conduct awareness programme to the parents of public examination - facing students employing counselor and psychological-sound experienced teachers. The parents should know that marks are not the only weapon to win the life.

\section{REFERENCES}

[1] Deb, S., Strodl, E., \& Sun, J. (2015). Academic stress, parental pressure, anxiety and mental health among Indian high school students. International Journals of Psychology and Behavioural Sciences, 5(1),26-34.

[2] Freedom from parental pressure. (n.d). Retrieved from https://sites.google.com/site/freedomfromparents/introduction-background-study

[3] Golden, S. A. R. (2011). An Analysis Of Mental Stress In Heavy Alloy Penetrator Project, Tiruchirapalli. SELP Journal of Social Science, 13.

[4] Golden, S. A. R. (2011). Problems and Prospectus of Distance Learning. Bharathidhasan University, 343, 344.

[5] Golden, S. A. R. (2011). Strategy For Success Of Human Beings:-Time Management. Department Of BBA, St. Joseph's College, Trichy, 388, 390. 
[6] https://www.bouddunan.com/articles/education/42-general/9268-examination-and-itsimportance.html

[7] Monica, S. B., \& Mary, A. P. (2016). Parental involvement and interpersonal intelligence of XI standard students. Research and Reflection on Education,14(3), 2-10.

[8] Naveen. (2009). Examination and importance. Retrieved from

[9] Regi, S. B., \& Golden, S. A. R. (2014). A Study On Educational Loan Availed By Students In Trichy City. Journal Of International Academic Research For Multidisciplinary (Jiarm), 2 (1).

[10] Tamil Nadu HSC Result 2016 Released Today, (2016). Retrieved from http://www.tn.results-nic.in/hsc-results.html

[11] Watson., T. S., \& Skinner., C. H. (2004). Encyclopedia of school psychology. New York: Klwer academic Publishers. 